\title{
Elder abuse: a common problem, commonly missed in trauma and orthopaedics
}

\author{
Chris Pereira ${ }^{1,2} \cdot$ Michael Fertleman $^{1,2}$ (1)
}

Received: 29 August 2019 / Accepted: 17 September 2019 / Published online: 22 October 2019

(c) Crown 2019

Since the first mention of elder abuse in medical literature as "granny bashing" in the mid-1970s, elder abuse remains under-researched, under-funded and under-diagnosed.

Elder abuse is common, with an estimated 141 million people affected globally each year [1]. This is likely to be the tip of the iceberg due to under-reporting and under-diagnosis, and the problem is only set to increase with an ageing global population. Elder abuse can be categorised into being physical, psychological, sexual, financial exploitation and abuse secondary to neglect, with overlap existing between these categories [2]. Physical elder abuse is associated with significant morbidity and mortality, as well as having a significant economic impact.

The human impact of elder abuse is striking. Patients are less able to recover from physical abuse and may have to undergo extensive rehabilitation programmes, which may still not be able to bring them back to their baseline function. There is a profound psychological impact upon patients, with increased rates of depression, anxiety, loss of confidence and self-esteem and increased suicidal ideation. Patients may never recover from their abuse, be that physically, psychologically or both [3].

Victims of elder abuse are likely to be from the most vulnerable sub-groups of older patients. Those most affected are usually those who are more socioeconomically deprived, have disabilities, have an increased dependence on others or have cognitive impairment [4]. Dementia is the strongest risk factor for elder abuse with behavioural and psychological symptoms of dementia (BPSD) a trigger and compounded by carer burnout syndrome. Whilst in the majority of cases next-of-kin will act in the patients best interest, this may not

Michael Fertleman

m.fertleman@imperial.ac.uk

1 Department of Geriatrics, Imperial College Healthcare NHS Trust, St. Mary's Hospital, London, UK

2 Department of Bioengineering, Imperial College London, London, UK always be the case, and the multidisciplinary team (MDT) should be wary of making this assumption [5].

Hospital visits offer a key opportunity to identify and act upon elder abuse, particularly in trauma and orthopaedics where physical abuse will be most apparent. A hospital admission may be the only time a vulnerable older person leaves the house, and their only interaction away from their caregiver and potential abuser. Social isolation is an important risk factor for elder abuse [6], and is likely to have increased following the economic downturn and cuts to government-funded social support networks.

Identifying elder abuse is undoubtedly challenging. The most important reason for this is that elder abuse can mimic injuries sustained from accidental trauma. It is well recognised that minor trauma can result in far more serious injuries in the elderly population, with $75 \%$ of trauma in the elderly being secondary to a simple fall from sitting or standing. This occurs for a variety of reasons including an increased number of pre-existing conditions, frailty, decreased physiological reserve, and medication use [7]. It is therefore easy to see why serious traumatic injuries in an elderly patient can be misattributed to a fall. There is also the possibility that a fall could have been caused by a patient being pushed, making it even harder to disentangle the true aetiology.

Further diagnostic challenges are that elderly patients may have cognitive frailty and not be able to recall events associated with their abuse. There may be cultural reasons for the patient not wanting to report abuse, or fear of retribution from the perpetrator, particularly if they are solely dependent upon them.

As Kavak and Özdemir highlight in their review on 'The Radiological Appearance of Physical Elder Abuse', injury patterns offer an important discerning feature. The paper highlights those injuries that are more typical of elder abuse. The upper limbs were the most commonly injured area, with upper limb fractures typically occurring in the distal and diaphyseal bone segments. This is important as distal 
bone fractures are associated with lower energy traumas, suggesting they were sustained after a victim was hit. The most common fracture site was the ribs. Fractures here were commonly multiple and nearly all of them occurred in the posterior segment. This is a striking finding and may suggest victims being attacked from behind. Overall injuries were mostly sustained on the left side of the body, in keeping with patients being hit by a right handed individual. There was a very high rate of old fractures on the imaging, a further important clue for healthcare professionals to consider.

As there are many obstacles to discovering elder abuse, a focussed approach from the MDT is required to identify it. A great deal can be learnt from the specialty of paediatrics, which has a more robust and thorough approach to discovering non-accidental injury (NAI) and a superior evidence base in how to tackle the problem.

The first lesson is one of education. The topic of paediatric NAI is embedded into the United Kingdom undergraduate and postgraduate paediatric curriculum for both doctors and nurses. The role radiology can play in identifying suspicious paediatric injury patterns was first identified over 70 years ago. There is also a better understanding and appreciation of paediatric NAI amongst other professions, such as the education, justice, police and social care sectors.

In terms of staffing, within paediatric departments there are named leads in safeguarding in all paediatric departments. Whilst hospitals have adult safeguarding leads, also known as adult protection in other countries, there are few named elder abuse-safeguarding leads. This is despite the fact the elderly patient group have specific needs and should be treated accordingly.

Lessons can also be learnt from how paediatric NAI cases are documented and escalated. Within paediatric safeguarding cases, there is typically a specially designed proforma to be completed, with a body map to record sites of injury. These must be completed by experienced senior pediatricians. Alongside this, strict protocols exist for how members of the paediatric team go about escalating suspected cases of NAI. There is often a $24-\mathrm{h}$ on call social worker to whom suspected case of paediatric abuse can be reported to.

It is likely that elder abuse will be discovered through a series of subtle clues. When considering a patient's admission under an orthopaedic team, all of the MDT members can play a role in its identification. The triage nurse in the emergency department may note a relative refuses to let a patient answer questions directed at them. A junior doctor may note multiple recent admissions with unexplained injuries and discrepancies within the collateral history. The patient's healthcare assistant could raise concerns about bruises on the inner thigh they might notice whilst washing a patient. A radiographer could politely enquire about the mechanism of a patient's injuries whilst they are alone together. The radiologist when reporting a patient's imaging may be able to objectively piece together various suggestive radiographic signs of abuse. The orthopaedic surgeon may be able to pick up that the injuries do not fit with the suggested timeline and represent a delayed presentation. An occupational therapist on a home visit could note poor living conditions and evidence of alcohol abuse in the home. A senior nurse on the ward may highlight strained interaction between a patient and their care giver. A physiotherapist may notice a patient flinching out of fear during their assessment. A dietician who reflects on why a patient has such a low albumin and poor nutritional state. The list goes on.

Every healthcare professional should be trained to recognise and act upon signs of elder abuse, as detailed in the European Charter of the Rights and Responsibilities of Older People in Need of Long-Term Care and Assistance [8]. Subtle clues of abuse may take time to come to light and be pieced together, so we must all remain vigilant throughout an elderly patient's admission. It is also worth considering the role a General Practitioner has in preventing elder abuse. They may have a clearer overview of recurrent orthopaedic admissions, the opportunity to carry out home visits and a unique insight into family dynamics and transgenerational violence.

Perhaps surprisingly, a systematic review of studies has shown that both vulnerable older people and their caregivers are willing to report elder abuse when directly asked about it [9]. It is striking that some caregivers are willing to admit committing abuse, despite the potential repercussions this may have upon themselves. This may reflect the profound challenges associated with being a full-time caregiver, and may be acting as a cry for help. It may also reflect the scale of the problem, given there are likely many other caregivers who are not prepared to be honest about abuse they have committed.

If a case of elder physical abuse is identified, this represents just the start of trying to help a vulnerable patient. Studies have shown that once physical elder abuse is identified, most patients are discharged back to the care of their abusers [10]. There are no high-quality randomised controlled trials to base how to effectively intervene in elder abuse. The current approach is that successful interventions must be multidisciplinary, ongoing and community based [11].

The jury is still out on a wide range of issues relating to elder abuse. In 2002, the WHO released 'The Toronto Declaration', a call for action to prevent elder abuse. This included the need for improved research to better understand the problem. In spite of this, there is little high-quality research into elder abuse. A Cochrane review has found there are clear evidence gaps in how to increase detection rates of elder abuse and programmes to try to prevent it occurring or recurring [2]. There is even less research about how to identify and tackle the subject in developing countries. 
In summary, the specialty of orthopaedics has a crucial role to play in the process of identifying elder abuse and protecting vulnerable elderly patients from devastating consequences. In a wider context, we as a society need to more readily recognise elder abuse. In the same way that domestic violence or child abuse was historically not seen as existing or as a private, family matter, we must confront these difficult realities head on. We must challenge the pervasive ageism of society to demand more research, more funding and better diagnosis and prevention. Countless numbers of vulnerable elderly patients are depending on us to do so.

\section{Compliance with ethical standards}

Conflict of interest The authors declare that they have no conflict of interest.

Ethical approval This article does not contain any studies with human participants performed by any of the authors.

Informed consent None.

\section{References}

1. Yon Y, Mikton CR, Gassoumis ZD, Wilber KH (2017) Elder abuse prevalence in community settings: a systematic review and meta-analysis. Lancet Glob Health 5(2):e147-e156. https://doi. org/10.1016/S2214-109X(17)30006-2

2. Baker PRA, Francis DP, Hairi NN, Othman S, Choo WY (2016) Interventions for preventing abuse in the elderly (Review). Cochrane Database Syst Rev. https://doi.org/10.1002/14651858. CD010321.pub2
3. Madrid International Plan of Action on Ageing/United Nations For Ageing. https://www.un.org/development/desa/ageing/madri d-plan-of-action-and-its-implementation.html. Accessed $13 \mathrm{Jul}$ 2019

4. Sethi D, Wood S, Mitis F et al (2011) European Report on Preventing Elder Maltreatment. http://www.euro.who.int/pubrequest . Accessed 9 Jul 2019

5. Tibullo L, Esquinas AM, Vargas M et al (2018) Who gets to decide for the older patient with a limited decision-making capacity: a review of surrogacy laws in the European Union. Eur Geriatr Med 1:3. https://doi.org/10.1007/s41999-018-0121-8

6. Soares JJF, Barros H, Torres-Gonzales F et al (2010) Among elderly in Europe among elderly in Europe abuse and health abuse and health 2. http://www.diva-portal.org/smash/get/diva2:37701 6/FULLTEXT01.pdf. Accessed 18 Jul 2019

7. Atinga A, Shekkeris A, Fertleman M, Batrick N, Kashef E, Dick E (2018) Trauma in the elderly patient. Br J Radiol. https://doi. org/10.1259/bjr.20170739

8. European Charter of the Rights and Responsibilities of Older People in Need of Long-Term Care and Assistance (2010). https:// www.age-platform.eu/sites/default/files/EuropeanCharter_EN.pdf. Accessed 18 Jul 2019

9. Cooper C, Selwood A, Livingston G (2008) The prevalence of elder abuse and neglect: a systematic review. Age Ageing 37:151160. https://doi.org/10.1093/ageing/afm194

10. Rosen T, Bloemen EM, LoFaso VM, Clark S, Flomenbaum NE, Lachs MS (2016) Emergency department presentations for injuries in older adults independently known to be victims of elder abuse. J Emerg Med 50(3):518-526. https://doi.org/10.1016/J. JEMERMED.2015.10.037

11. Lachs MS, Pillemer K (1995) Abuse and neglect of elderly persons. N Engl J Med 332(7):437-443. https://doi.org/10.1056/ NEJM199502163320706

Publisher's Note Springer Nature remains neutral with regard to jurisdictional claims in published maps and institutional affiliations. 